\title{
When to Fire Bad Managers: The Role of Collusion between Management and the Board of Directors
}

Citation for published version (APA):

Beetsma, R., Peters, H. J. M., \& Rebers, E. (2000). When to Fire Bad Managers: The Role of Collusion between Management and the Board of Directors. Journal of Economic Behavior \& Organization, 42(4), 427-444. https://doi.org/10.1016/S0167-2681(00)00098-6

Document status and date:

Published: 01/01/2000

DOI:

10.1016/S0167-2681(00)00098-6

Document Version:

Publisher's PDF, also known as Version of record

\section{Please check the document version of this publication:}

- A submitted manuscript is the version of the article upon submission and before peer-review. There can be important differences between the submitted version and the official published version of record.

People interested in the research are advised to contact the author for the final version of the publication, or visit the DOI to the publisher's website.

- The final author version and the galley proof are versions of the publication after peer review.

- The final published version features the final layout of the paper including the volume, issue and page numbers.

Link to publication

\footnotetext{
General rights rights.

- You may freely distribute the URL identifying the publication in the public portal. please follow below link for the End User Agreement:

www.umlib.nl/taverne-license

Take down policy

If you believe that this document breaches copyright please contact us at:

repository@maastrichtuniversity.nl

providing details and we will investigate your claim.
}

Copyright and moral rights for the publications made accessible in the public portal are retained by the authors and/or other copyright owners and it is a condition of accessing publications that users recognise and abide by the legal requirements associated with these

- Users may download and print one copy of any publication from the public portal for the purpose of private study or research.

- You may not further distribute the material or use it for any profit-making activity or commercial gain

If the publication is distributed under the terms of Article $25 \mathrm{fa}$ of the Dutch Copyright Act, indicated by the "Taverne" license above, 


\title{
When to fire bad managers: the role of collusion between management and board of directors
}

\author{
Roel Beetsma ${ }^{\mathrm{a}}$, Hans Peters $^{\mathrm{b}, *}$, Eugène Rebers $^{\mathrm{c}}$ \\ ${ }^{a}$ Dutch Ministry of Economic Affairs CEPR, Den Haag, The Netherlands \\ ${ }^{\mathrm{b}}$ Department of Quantitative Economics, University of Maastricht, P.O. Box 616, 6200 MD, \\ Maastricht, The Netherlands \\ ${ }^{c}$ Dutch Ministry of Finance, Den Haag, The Netherlands
}

Received 28 April 1998; received in revised form 26 May 1999; accepted 27 May 1999

\begin{abstract}
We develop a model in which a shareholder hires a director to monitor a manager who faces stochastic firing costs. We study the optimal incentive scheme for the director, allowing for the possibility that the manager bribes the director in order to change his firing intentions. Such collusion may be in the interest of the shareholder, because it avoids the need to (ex ante) compensate the manager for very high realisations of his firing costs (these are precisely the cases in which collusion occurs). () 2000 Elsevier Science B.V. All rights reserved.
\end{abstract}

JEL classification: J33; L22

Keywords: Corporate governance; Hierarchies; Incentive compensation; Collusion; Board of directors

\section{Introduction}

Even among capitalist economies, there are pronounced differences in the way corporations are run. In the US and the UK, for example, most of the large firms are supervised by a Board of Directors (BoD). The $\mathrm{BoD}$ is composed of outside directors as well as executive directors, who are involved in the day-to-day management of the firm. The ultimate power, however, rests with the shareholders, who always have the possibility to fire the management. The Anglo-Saxon system is therefore often cited as an example of how corporate governance should be organised in countries where shareholders have much less influence on the way the company is run.

In Germany and the Netherlands, it is common to have a separation between the management and the BoD. In such a two-tier system, the BoD often acts as an autonomous body

\footnotetext{
* Tel.: +31-43-388-3834; fax: +31-43-388-4874.

E-mail address: h.peters@ke.unimaas.nl (H. Peters) 
which is beyond the control of the shareholders. ${ }^{1}$ It is frequently argued that this lack of shareholder power gives rise to situations in which the management and the BoD mutually protect each other at the expense of the shareholder. ${ }^{2}$ In this paper, however, we argue that such collusion between management and directors is not always bad for the shareholders.

To show why this may be the case, we consider a simple two-period model of a firm which hires a manager at the start of the first period. The match between the manager and the firm may turn out to be either good or bad. The quality of the match is beyond the control of the manager or the firm: it is merely a 'move by Nature'. If the match is bad, the shareholder would like to fire the manager at the end of the first period. ${ }^{3}$

At that moment, the manager learns about the size of a personal cost that he will incur in the event of being fired. In practice, the firing cost can take several forms. For example, it may capture foregone income as well as the loss of resources in the process of searching for a new job and moving to another place. But there may also be other, less tangible costs, such as the loss of reputation and valuable contacts. It is reasonable to assume that these costs are, at least partly, unknown ex ante, for example because it is not clear what the manager's job market position or legal position will be in the future. However, for the manager to be willing to run the firm, he needs to be ex ante compensated for his expected firing cost.

In the ideal situation, the shareholder would observe this firing cost also and be able to commit ex ante to not firing the manager in those cases in which his firing cost exceeds the expected gain from hiring a new manager. Rather realistically, we assume that the shareholder can only learn about the quality of the match through the observation of the firm's first-period cash-flow. Moreover, the shareholder does not observe the realisation of the firing cost. Therefore, the shareholder may want to delegate the power whether or not to fire the manager to a director who monitors the company more closely and thus can make better informed decisions. If the firing cost of a (bad) manager turns out to be relatively high, he has the incentive to bribe the director not to fire him. The possibility of such collusion may be in the interest of the shareholder, because it saves him the resources needed to compensate the manager it ex ante for potentially high realisations of the firing cost. Thus, collusion avoids part of the deadweight losses associated with firing decisions.

The model is primarily meant to analyse a two-tier corporate governance system, in which the BoD (the Supervisory Board) is independent of the management and thus has the power to fire the management. It could also apply to a one-tier system if the Board includes a number of outside (non-executive) directors, who perform a monitoring role similar to the one carried out by the BoD in the two-tier system. In that case, the outside directors might be bribed by the executive directors to induce them to fulfil their monitoring role less zealously. However, a crucial assumption for the results to hold is that the BoD be

\footnotetext{
${ }^{1}$ In the Netherlands, only the BoD has a right to appoint or to fire the management. The BoD also appoints its own successors, without interference from the shareholders (see, for example, Moerland (1995)).

${ }^{2}$ Examples for the Netherlands are the companies Nedlloyd, Vie d'Or and Bobel. In the cases of Nedlloyd (Volkskrant, 1993a) and Bobel (NRC, 1996), directors failed to exert sufficient control, while in the case of Vie d'Or, directors and managers were involved jointly in outright fraud (Volkskrant, 1993b, 1997). Of course, only cases that end badly get attention from the media. Examples of beneficial collusion between management and BoD rarely get into the press.

${ }^{3}$ With some slight abuse of terminology, we will refer to the manager as being good (bad) if the quality of the match between the manager and the firm is good (bad).
} 
independent of the shareholders. If not, as is usually the case in the one-tier system, the way it is applied in the US and the UK, the possible collusion mechanism would break down. The reason is that the shareholders can always get rid of a bad manager, no matter how large his personal firing cost is. In the two-tier system, a breakdown of the mechanism is likely if large shareholders are represented on the Board. The size of the bribe needed to compensate such Board members for the expected loss from retaining a bad manager may well be too large for him to pay. In the model, we assume that the Board is independent, and hence, that large shareholders are not on the Board.

For simplicity, the model assumes that collusion between the manager and the director takes place through a monetary transfer from the former to the latter. In reality, however, such a bribe would often be less tangible. For example, in a corporate system with interlocking directorships and strong informal ties across firms the manager might recommend the director at other firms for a directorship. Another example would be a tightening of buyer-seller relations between the manager's firm and firms in which the director has a stake or of which he is manager himself.

To focus on the question under what circumstances collusion can be beneficial, we keep the model as simple as possible by ignoring the effect that manager effort can have on the firm's performance. However, there is large principal-agent literature that focuses on designing compensation schemes that a shareholder can use to extract the optimal level of effort from a manager. ${ }^{4}$ This standard model has been extended to incorporate a supervisor as another layer between the principal and the agent (e.g. Baron and Besanko, 1984). According to Kofman and Lawarree (1993), however, 'the research in this area has by and large neglected the possibility of collusion.'

An important exception is Tirole (1986), who adds a set of 'coalition incentive compatibility constraints' to the usual individual rationality and incentive compatibility constraints, such that the final allocation is coalition-proof. Kofman and Lawarree (1996) develop a model in which it may be optimal for the principal to allow for collusion. However, this result is obtained because deterring collusion is costly in their model. In contrast, in our model, even if it is costless to prevent collusion, allowing for collusion between management and director can be beneficial to the principal.

Our argument is developed in the following steps. Section 2 presents the basic model. In Section 3, we study from the shareholder's point of view the ideal benchmark case where the shareholder after one period observes the manager's type and his firing cost, and from the start can commit to a firing rule based on the realisation of the firing costs. Section 4 relaxes these assumptions in the sense that the shareholder only receives only a noisy signal in the form of a realisation of the firm's cash-flow, on which he bases the firing decision.

The next step (Section 5) then is to delegate the firing decision to a director, who has an information advantage because he monitors the manager more closely. The salary of the director depends on the cash-flow of the firm. The manager receives a fixed salary as well as a fixed severance payment which is paid only when he is fired. As a higher severance payment reduces the incentive of a bad manager to bribe the director, the shareholder would want to set it as high as possible if collusion is undesirable. However, in those cases in

\footnotetext{
${ }^{4}$ For example, Ross (1973), Holmstrom (1979), and Grossman and Hart (1983). For empirical evidence on incentive compensation, see, for example, Jensen and Murphy (1990) and Garen (1994).
} 
which it is desirable to allow for collusion, the severance payment will help to ensure that firing takes place only when the realised firing cost is relatively low.

Section 6 explores under what conditions the shareholder would allow for the possibility of collusion, even if he were able to prevent it without any cost. This bears upon the debate whether the shareholder position in Germany and the Netherlands should be strengthened, or more specifically, whether regulators or corporate law should give shareholders more instruments to prevent collusion if they wish to do so (for example, stricter information disclosure rules, more powers to fire managers or directors). Section 7 concludes the paper.

\section{The basic model}

We consider a two-period model without discounting and in which all agents are riskneutral. Qualitatively speaking, the assumption of risk neutrality does not affect our results. A firm is owned by a shareholder ${ }^{5}$, who randomly selects a manager at the start of the first period. The cash-flow generated by the firm in any given period depends on how the firm and the manager fit together. At the moment the manager is selected, neither he nor the shareholder knows how good the match will be. A manager fits the firm well if he is 'the right man at the right time at the right place'. Such a manager is called a 'good' manager. A manager who does not fit the firm well is called a 'bad' manager.

The firm's cash-flow in a given period, $x$, is stochastic. It depends not only on the type of the manager but also on random factors which are beyond his control. If the manager is good, the distribution of the cash-flow is described by a density function $f_{\mathrm{G}}(x)$. Similarly, if he is bad, the density function of the cash-flow is $f_{\mathrm{B}}(x)$. Details about the density functions are reported in Fig 1. Both density functions are restricted to the domain $[0, X], X>0$. They are linear with a slope $2 / X^{2}$ for the good manager and a slope $-2 / X^{2}$ for the bad manager. Thus, it is likely that the good manager produces a higher cash-flow. ${ }^{6}$ The expected cash-flow of the firm when the manager is good (bad) is $\mu_{\mathrm{G}}\left(\mu_{\mathrm{B}}\right)$. Without loss of generality, we assume that the a priori probabilities of the manager being good or bad, $\operatorname{Pr}\{\mathrm{G}\}$ and $\operatorname{Pr}\{\mathrm{B}\}$, respectively, are both equal to $1 / 2$. Hence, the expected cash-flow generated by a randomly selected manager is $\bar{\mu} \equiv \operatorname{Pr}\{\mathrm{B}\} \mu_{\mathrm{B}}+\operatorname{Pr}\{\mathrm{G}\} \mu_{\mathrm{G}}$. On account of the assumed symmetry, $\mu_{\mathrm{G}}-\bar{\mu}=\bar{\mu}-\mu_{\mathrm{B}} \equiv \Delta \mu$. Hence, $\Delta \mu$ is the (absolute) difference between the average expected cash-flow and the expected cash-flow under a good or bad manager.

Managers have a reservation wage of $W_{\mathrm{m}}>0$ in each period. At the end of the first period, the manager can either be retained or be fired and replaced by another manager. This decision will of course depend on the available information about the type of the manager, as we will see below. A manager who is fired incurs a personal firing cost $c$. The firing cost is stochastic and uniformly distributed on the interval $[0, C]$. We assume that it

\footnotetext{
${ }^{5}$ For convenience, we refer to 'the shareholder' in the text. However, 'the shareholder' can be viewed as a group of small shareholders taken together.

${ }^{6}$ The choice of these specific density functions is made for convenience of exposition. The basic characteristic is that the stochastic cash-flow generated by the good manager first-degree stochastically dominates the cash-flow generated by the bad manager. As long as this stochastic dominance relation holds, our results will be qualitatively unaffected by the use of more general functional forms. This is also the case if the ex ante probabilities of the manager being good or bad are no longer equal and if the distribution of the firing cost $c$, below, is no longer uniform.
} 
Bad manager:

A priori probability $\operatorname{Pr}(B)=\frac{1}{2}$

$f_{B}(x)=\frac{2}{X}-\frac{2}{X^{2}} x$

$\mu_{B}=\frac{1}{3} X$

Good manager:

A priori probability $\operatorname{Pr}(G)=\frac{1}{2}$

$f_{G}(x)=\frac{2}{X^{2}} x$

$\mu_{G}=\frac{2}{3} X$

Note that:

$\bar{\mu}=\operatorname{Pr}(B) \mu_{B}+\operatorname{Pr}(G) \mu_{G}=\frac{1}{2} X$

$\left(\bar{\mu}-\mu_{B}\right)=\left(\mu_{G}-\bar{\mu}\right) \equiv \Delta \mu=\frac{1}{6} X$ $f(x) \uparrow$

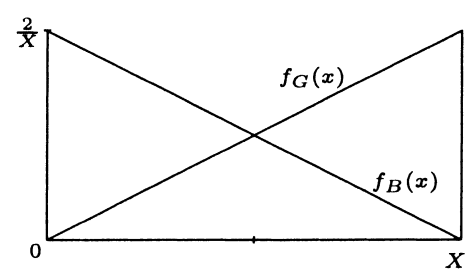

$\rightarrow$

Fig. 1. The cash-flow density functions of the two types of managers.

is (statistically) independent of the cash-flow under either type of manager. The realisation of the firing cost is revealed to the manager at the end of the first period.

To induce the manager to run the firm, he must be compensated somehow for his expected firing cost, which we denote by $c^{\mathrm{e}}$. Of course, $c^{\mathrm{e}}$ depends on the probability that the manager will be fired. This, in turn, depends on the specific arrangements (e.g., a director who can be bribed) to be considered below. Compensation takes place through a fixed salary $s$, and a fixed severance payment, $p \geq 0$, which the manager receives in the case he gets fired. ${ }^{7}$ Hence, in the first period, his participation constraint is given by

$$
W_{\mathrm{m}} \leq s+p^{\mathrm{e}}-c^{\mathrm{e}},
$$

where $p^{\mathrm{e}}$ is his expected severance payment (which depends also on the probability that the manager will be fired).

If the manager is not fired at the end of the first period, he will receive a fixed wage $W_{\mathrm{m}}$ in the second period. If he is fired, he is assumed to be able to obtain his second-period reservation wage somewhere else.

\section{The first best}

The shareholder's payoff is maximised if he can observe perfectly both the type of the manager and his firing cost at the end of the first period, and if he can commit ex ante (i.e., at the start of the first period when contracts are signed) to a firing rule which depends on the realised firing cost. The resulting solution will be termed the first best. ${ }^{8}$

Firing a bad manager and replacing him with a randomly selected new manager at the end of the first period raises the expected cash-flow of the firm in the second period by $\Delta \mu$, while firing a good manager reduces the expected future cash-flow of the firm by $\Delta \mu$. To

\footnotetext{
${ }^{7}$ Note that, if the firing decision does not depend on the value of $p$, compensation for expected firing costs could instead take place through a higher $s$. The distinction between $s$ and $p$ becomes relevant only in Section 5.2.

${ }^{8}$ Strictly speaking, the ideal situation for a shareholder would be if he knew the type of the manager at the start of the first period. This case is trivial and is, therefore, neglected.
} 
induce a manager to run the firm, he has to be compensated for his expected firing costs. While ex post, the shareholder would always want to fire a bad manager, from an ex ante point of view, in those cases in which the realised firing cost exceeds the expected increase in the second-period cash-flow of the firm, the shareholder would not want to fire the manager.

Suppose first that $C \leq \Delta \mu$. Even from an ex ante point of view, the shareholder would always want to fire a bad manager. Hence, the value of commitment to an optimal firing rule, based on the realised firing cost, is 0 .

Now suppose that $C>\Delta \mu$. Ex ante, it would be optimal to fire only if $c<\Delta \mu$ and not to fire if $c \geq \Delta \mu$. The value of commitment for the shareholder is the sum of two components. The first component is the reduction in the compensation that the manager requires for the expected firing cost he incurs, $(1 / 2) \bar{C}-(1 / 2)(\Delta \mu / C)(1 / 2) \Delta \mu$, where $\bar{C} \equiv E[c]=(1 / 2) C$. Here, $(1 / 2) \bar{C}$ is the compensation he requires if he is always fired when he turns out to be bad. If the shareholder can commit himself to only firing a bad manager if $c<\Delta \mu$, the manager requires a compensation of $(1 / 2)(\Delta \mu / C)(1 / 2) \Delta \mu$. This is the probability that he is bad, $1 / 2$, times the probability that $c<\Delta \mu$, times the expected firing cost conditional on $c<\Delta \mu$, which equals (1/2) $\Delta \mu$. The second component is (minus) the reduction in the expected second-period cash-flow from not always firing a bad manager in the case of commitment, $(1 / 2) \Delta \mu-(1 / 2)(\Delta \mu / C) \Delta \mu$. Always (instead of never) firing a bad manager raises the expected cash-flow with the probability that the manager is bad, $1 / 2$, times the expected increase in the cash-flow from firing the bad manager, $\Delta \mu$. Only firing a bad manager if $c<\Delta \mu$ merely raises the expected cash-flow by the probability that the manager is bad, times the probability that $c<\Delta \mu,(\Delta \mu / C)$, times the expected increase in the cash-flow from firing the bad manager. Hence, the value of commitment is

$$
\left[\frac{1}{2} \bar{C}-\frac{1}{2}\left(\frac{\Delta \mu}{C}\right) \frac{1}{2} \Delta \mu\right]-\left[\frac{1}{2} \Delta \mu-\frac{1}{2}\left(\frac{\Delta \mu}{C}\right) \Delta \mu\right]=\frac{1}{4} \frac{(C-\Delta \mu)^{2}}{C} .
$$

Not surprisingly, for given $\Delta \mu(<C)$, the value of commitment is increasing in $C$.

\section{No director}

From now on, we assume that the shareholder observes neither the type of the manager nor his firing cost at the end of the first period. ${ }^{9}$ Therefore, the only information upon which the shareholder can base his firing decision is the realisation of the first-period cash-flow, $x_{1}$. More specifically, at the start of the first period, the firm and the manager sign a contract which specifies a fixed threshold $\tau$ for $x_{1}$. The manager will be fired at the end of the first period if and only if $x_{1}<\tau$.

The shareholder chooses the threshold $\tau$ so as to maximise his expected payoff. ${ }^{10}$ The only relevant variables that enter his objective function are the expected cash-flow of the

\footnotetext{
${ }^{9}$ We assume also that, in the absence of a director, the manager is not able to observe his own type at the end of the first period. This precludes the possibility of a long-term revelation contract between the shareholder and the manager such that the first best (see Section 3) is achieved.

${ }^{10}$ One can show that the optimal threshold yields the highest payoff to the shareholder of all possible contracts where the choice to fire or not is based on $x_{1}$ only.
} 
firm in the second period, denoted by $x_{2}^{\mathrm{e}}$, the fixed salary of the manager in the first period, and the expected severance payment at the end of the first period. These are the variables that depend on the firing decision, and hence, are affected by the threshold. As there is no reason to pay the manager more than his reservation wage, the participation constraint of the manager will be binding. Hence, using Eq. (1) with equality, one has

$$
\mathrm{SV}=x_{2}^{\mathrm{e}}-s-p^{\mathrm{e}}=x_{2}^{\mathrm{e}}-W_{\mathrm{m}}-c^{\mathrm{e}},
$$

where SV is the shareholder value. Throughout, we thus ignore the manager's second-period salary as well as the contribution of the expected first-period cash-flow $(\bar{\mu})$ to the shareholder value. This is irrelevant for any of the results.

We can write Eq. (3) as

$$
\mathrm{SV}=\bar{\mu}-W_{\mathrm{m}}+\frac{1}{2}\left[F_{\mathrm{B}}(\tau)-F_{\mathrm{G}}(\tau)\right] \Delta \mu+\frac{1}{2}\left[F_{\mathrm{B}}(\tau)+F_{\mathrm{G}}(\tau)\right] \bar{C},
$$

where $F_{\mathrm{B}}($.$) and F_{\mathrm{G}}($.$) are the distribution functions corresponding to f_{\mathrm{B}}($.$) and f_{\mathrm{G}}($.$) ,$ respectively.

The intuition for Eq. (4) is as follows. If the shareholder would never fire a manager ( $\tau=$ 0 ), the shareholder value is simply the average cash-flow of the firm minus the reservation wage of the manager $\left(\bar{\mu}-W_{\mathrm{m}}\right)$. If a threshold $\tau>0$ is imposed, the shareholder will fire a bad manager with probability $(1 / 2) F_{\mathrm{B}}(\tau)$, which is the probability that the manager is bad times the probability that $x_{1}<\tau$, given that the manager is bad. Similarly, the shareholder will fire a good manager with probability $(1 / 2) F_{\mathrm{G}}(\tau)$, which reduces the expected second-period cash-flow by $\Delta \mu$. Finally, the expected cost of setting a threshold is $(1 / 2)\left[F_{\mathrm{B}}(\tau)+F_{\mathrm{G}}(\tau)\right] \bar{C}$. This is the probability that the manager is fired, $(1 / 2)\left[F_{\mathrm{B}}(\tau)+F_{\mathrm{G}}(\tau)\right]$, times his average firing cost, $\bar{C}$.

Differentiating the right-hand side of Eq. (4) yields the necessary, and in this case, sufficient first-order condition for $\tau$ :

$$
\bar{C}=\left(\frac{f_{\mathrm{B}}(\tau)-f_{\mathrm{G}}(\tau)}{f_{\mathrm{B}}(\tau)+f_{\mathrm{G}}(\tau)}\right) \Delta \mu .
$$

Hence, the optimal threshold, denoted by $\tau^{*}$, is

$$
\tau^{*}=\frac{1}{2} X\left(1-\frac{\bar{C}}{\Delta \mu}\right), \quad \text { if } \bar{C}<\Delta \mu,
$$

where we have used the distributional properties reported in Fig. 1. If $\bar{C} \geq \Delta \mu$, the shareholder sets $\tau^{*}=0$. As the expected firing cost exceeds the expected increase in the cash-flow of the firm in this case, it is optimal not to impose a positive threshold. Eq. (6) shows that the threshold is always below (1/2)X. Moreover, $\tau^{*}$ is positively related to $\Delta \mu$ and negatively related to $\bar{C}$. An increase in $\Delta \mu$ raises the likelihood that a below-average performance, i.e. $x_{1}<(1 / 2) X$, can be attributed to the manager being bad. Ceteris paribus, an increase in $\bar{C}$ raises the expected firing cost for the manager and thus requires the shareholder to offer him a higher salary. To compensate for this, the shareholder sets a higher threshold, thereby reducing the probability that the manager will be fired. 
Finally, for $\tau=\tau^{*}$, the shareholder value is

$$
\mathrm{SV}= \begin{cases}\bar{\mu}-W_{\mathrm{m}}+\frac{1}{4} \Delta \mu-\frac{1}{2} \bar{C}\left(1-\frac{1}{2} \frac{\bar{C}}{\Delta \mu}\right), & \text { if } \bar{C}<\Delta \mu, \\ \bar{\mu}-W_{\mathrm{m}}, & \text { if } \bar{C} \geq \Delta \mu .\end{cases}
$$

Higher average firing costs reduce the shareholder value (if $\bar{C}<\Delta \mu$ ). The reason is that the shareholder has to compensate the manager for the higher expected firing cost by increasing his salary accordingly.

The current arrangement involving a threshold is dominated by the first best (see Section 3) for two reasons. The first is that the shareholder no longer perfectly observes the type of the manager. He can make either one of two errors: firing a good manager or not firing a bad manager. The second reason is that, because the shareholder does not observe the realisation of the firing cost, he cannot commit himself to not firing the manager if $c \geq \Delta \mu$.

\section{Introducing a director}

From now on, the shareholder can delegate the firing decision to an independent director. The director may be expected to have more information about the manager than the shareholder. According to Fama (1980), the director can be viewed as a market-induced institution, ' $[\ldots]$ whose most important role is to scrutinize the highest decision makers in the firm.' In particular, we assume that, while the shareholder is not able to observe the manager's type, the director can observe his type perfectly at the end of the first period. In practice, stock ownership is often so widely dispersed that it is not worthwhile for an individual shareholder to monitor a firm closely. In contrast to the shareholder, the director frequently interacts with the manager, making it easier for the director to establish the manager's type. In addition, the director often is a director at other firms as well. Comparing the performance of these other firms with the firm under consideration enables the director to infer whether the manager is good or bad. Finally, we assume that also the manager himself observes his type only at the end of the first period. This should not be unreasonable for a firm in which the manager interacts with his director on a sufficiently frequent basis.

The reservation wage of the director is $W_{\mathrm{d}}>0$. We assume that $W_{\mathrm{d}}$ is not too large because otherwise it would not be worthwhile to have a director at all. Specifically, it turns out that the following restriction will be convenient:

$$
W_{\mathrm{d}} \leq\left(\bar{\mu}+\frac{1}{2} \Delta \mu\right) \operatorname{Min}\left[1, \frac{C}{\Delta \mu}\right] .
$$

We assume that the director receives a proportion $\alpha \geq 0$ of the second-period cash-flow of the firm. This should give him an incentive, albeit not always a perfect one, to make the appropriate firing decision from the viewpoint of the shareholder. Such a simple, linear incentive scheme can be motivated as follows. First, it captures the spirit of most of the incentive schemes implemented in practice, namely providing a simple link between reward and performance. Second, it yields the basic result of this paper, i.e., that collusion can be beneficial for the shareholder. This result also holds for more sophisticated incentive schemes (see Footnote 15 below). 
As the shareholder cannot observe the manager's type, there is a potential for collusion between the manager and the director. More specifically, we allow for the possibility that the manager offers a bribe to the director in order to influence his firing decision.

The shareholder value, the participation constraint of the manager, and the participation constraint of the director, are given by, respectively

$$
\begin{aligned}
& \mathrm{SV}=x_{2}^{\mathrm{e}}-s-p^{\mathrm{e}}-\alpha x_{2}^{\mathrm{e}}, \\
& W_{\mathrm{m}} \leq s+p^{\mathrm{e}}-c^{\mathrm{e}}-b^{\mathrm{e}}, \\
& W_{\mathrm{d}} \leq \alpha x_{2}^{\mathrm{e}}+b^{\mathrm{e}},
\end{aligned}
$$

where $b^{\mathrm{e}}$ is the expected bribe paid by the manager to the director in order to influence his firing decision.

\subsection{No collusion}

For the moment, we disregard the possibility of collusion. Hence, $b^{\mathrm{e}}$ drops out of Eqs. (10) and (11). Therefore, the payoff to the director depends only on the second-period cash-flow of the firm. Hence, for any $\alpha>0$, the director will always fire a bad manager, but never fire a good manager. Therefore, firing takes place with probability $1 / 2$. This implies that $x_{2}^{\mathrm{e}}=(1 / 2) \bar{\mu}+(1 / 2) \mu_{\mathrm{G}}=\bar{\mu}+(1 / 2) \Delta \mu$. The expected firing cost is $(1 / 2) \bar{C}$, which is the probability that a manager is bad multiplied by the average firing cost.

Define $\alpha^{0}$ as the minimum value of $\alpha$ for which the participation constraint of the director, Eq. (11), is satisfied. Hence,

$$
\alpha^{0}=\frac{W_{\mathrm{d}}}{\bar{\mu}+(1 / 2) \Delta \mu}>0 .
$$

Observe that $\alpha^{0} \leq 1$, as implied by Eq. (8). As the firing decision of the director is independent of $\alpha$ (if $\alpha>0$ ), it is optimal for the shareholder to set $\alpha=\alpha^{0}$. Combined with the fact that Eq. (10) is binding, this implies that

$$
\mathrm{SV}=\bar{\mu}+\frac{1}{2} \Delta \mu-W_{\mathrm{m}}-\frac{1}{2} \bar{C}-W_{\mathrm{d}} .
$$

To compare this with the shareholder value in the absence of a director, one has to distinguish between the case in which the shareholder would choose to set $\tau^{*}=0$ (i.e., if $\bar{C} \geq \Delta \mu$ ) and the case in which he would set $\tau^{*}>0$ (i.e., if $\bar{C}<\Delta \mu$ ).

$\overline{\bar{C}} \geq \Delta \mu$ : Comparing Eq. (13) and the second line of Eq. (7), we see that the shareholder would want to hire a director if and only if

$$
W_{\mathrm{d}} \leq \frac{1}{2}(\Delta \mu-\bar{C}) .
$$

Hence, in this case (because $\bar{C} \geq \Delta \mu$ ), the shareholder would never hire a director. The intuition is straightforward. The director, who observes the type of the manager perfectly, will always fire a bad manager. However, he does not take into account the (ex ante) compensation that the manager requires for his expected firing cost, $\bar{C}$, which exceeds the increase in the expected second-period cash-flow from always firing a bad manager. 
$\bar{C}<\Delta \mu$ : Comparing Eq. (13) and the first line of Eq. (7), it follows that the shareholder would hire a director if and only if

$$
W_{\mathrm{d}} \leq \frac{1}{4} \Delta \mu\left[1-\left(\frac{\bar{C}}{\Delta \mu}\right)^{2}\right] .
$$

As the right-hand side of Eq. (15) is positive, a director is hired if his reservation wage is not too high. Hiring a director is more profitable if $\Delta \mu$ is larger and if the average firing cost, $\bar{C}$, is lower.

\subsection{Collusion}

Now we allow for the possibility that the manager pays a bribe to the director at the end of the first period in order to influence his firing decision. The shareholder takes this into account when setting the compensation schemes at the start of the first period. He optimises over $\alpha, s$ and $p$. As the severance payment is paid only when the manager is fired, it will affect the expected bribe. Hence, there is an independent role for the severance payment now.

Fig. 2 shows the extensive form representation of the new game. At the start of the first period the shareholder (S) selects $\alpha, p$ and $s$. At the end of the first period there is a move by nature $(\mathrm{N})$ concerning the realisation of the firing cost, $c$, and the type of the manager. The manager, $\mathrm{G}(\mathrm{ood})$ or $\mathrm{B}(\mathrm{ad})$, each possibility with probability $1 / 2$, can then offer a 'take-it-or-leave-it' bribe to the director in order to influence his firing decision. The offer is denoted by the combination $\left(b_{\mathrm{F}}, b_{\mathrm{NF}}\right)$ and has the following form: "I pay you $b_{\mathrm{F}}$ if you fire me and $b_{\mathrm{NF}}$ if you do not fire me." On the basis of this offer, the director either fires (F) the manager or does not fire (NF) him (decision nodes D). We assume that the manager and the director both stick to the agreement, if the latter accepts the offer. ${ }^{11}$

Fig. 2 also shows the (expected) payoffs for each outcome. As before, we include only those variables that are affected by the actions in the game tree. It is easy to derive the payoffs from Eqs. (9)-(11). As the game is one of perfect information, we can use backwards induction to solve for a subgame perfect Nash equilibrium.

The first step is to investigate the incentives of the director to fire the manager at the end of the first period. In Section 5.1 we saw that, in the absence of collusion, the director will always fire a bad manager and never fire a good manager. If collusion is allowed, both a bad manager and a good manager may have an incentive to bribe the director in order to change his firing intentions. A bad manager would be prepared to offer a bribe of up to $(c-p)$ if this induces the director to not fire him. The director accepts this bribe if it is not lower than his expected gain from firing $(\alpha \Delta \mu)$. Therefore, if $c \geq p+\alpha \Delta \mu$, the bad manager successfully offers a bribe of $\alpha \Delta \mu$ and is not fired. A good manager would be

\footnotetext{
${ }^{11}$ The assumption of the manager having the right to make a take-or-leave-it bribe has an element of arbitrariness. Although it is the manager who may be fired and therefore offers a bribe, one could also imagine the director blackmailing the manager, and thus, asking for a bribe. Changing the order of the game by having the director move first (proposing a bribe) or including some bargaining on the size of the bribe would change the distribution of the surplus of collusion between the director and the manager (e.g., in the present set-up the manager extracts maximal gain from collusion). Consequently, it might change the values of $\alpha, p$ and $s$ in equilibrium. Beyond this, it would not change the results of the paper in any qualitative way.
} 


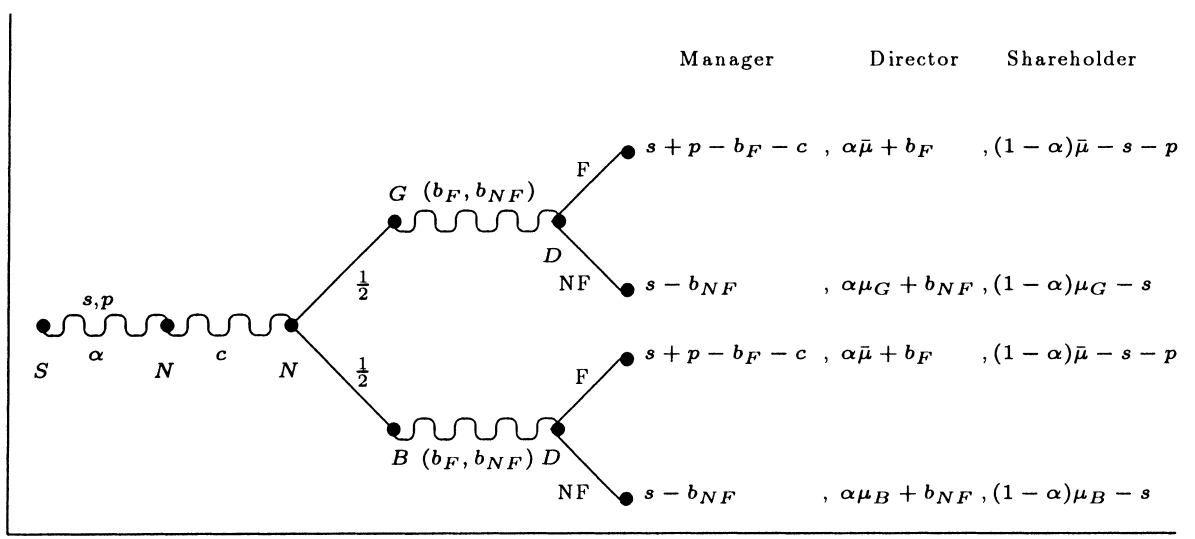

Fig. 2. Extensive form representation of the game if collusion is possible.

prepared to offer a bribe of up to $(p-c)$ if this induces the director to fire him. This bribe is accepted if it equals or exceeds the director's expected loss from firing a good manager $(\alpha \Delta \mu)$. Therefore, if $c \leq p-\alpha \Delta \mu$, the good manager successfully offers a bribe of $\alpha \Delta \mu$ and is fired.

However, we argue that, at an optimum $\left(\alpha^{*}, p^{*}\right)$, it should be the case that $p^{*} \leq \alpha^{*} \Delta \mu$ : hence, a good manager is never fired. Suppose that the opposite holds. Then, for every realisation of $c$ smaller than $\left(p^{*}-\alpha^{*} \Delta \mu\right)$, a good manager will succeed in bribing the director to fire him. However, such a value for $p$ cannot be optimal: reducing $p$ to $\alpha^{*} \Delta \mu$ increases the probability that a bad manager is not fired, but to the same extent, also decreases the probability that a good manager is fired. Therefore, the net effect on the expected cash-flow of the firm is nil, while the expected firing cost is reduced (so that $s+p^{\mathrm{e}}$ is reduced).

A bad manager is fired with probability $((p+\alpha \Delta \mu) / C) \leq 1$. This inequality holds at an optimum because any choices of $p$ and $\alpha$ such that $p+\alpha \Delta \mu>C$ can be improved upon by decreasing $\alpha$ : this does not change the incentives for the director but it increases the shareholder value. Hence, one has

$$
\begin{aligned}
x_{2}^{\mathrm{e}} & =\frac{1}{2} \mu_{\mathrm{G}}+\frac{1}{2}\left(\frac{C-p-\alpha \Delta \mu}{C} \mu_{\mathrm{B}}+\frac{p+\alpha \Delta \mu}{C} \bar{\mu}\right)=\bar{\mu}+\frac{1}{2} \frac{p+\alpha \Delta \mu}{C} \Delta \mu, \\
p^{\mathrm{e}} & =\frac{1}{2} \frac{p+\alpha \Delta \mu}{C} p, \\
c^{\mathrm{e}} & =\frac{1}{2} \frac{p+\alpha \Delta \mu}{C} \frac{1}{2}(p+\alpha \Delta \mu), \\
b^{\mathrm{e}} & =\frac{1}{2} \frac{C-p-\alpha \Delta \mu}{C} \alpha \Delta \mu .
\end{aligned}
$$

The director receives a proportion $\alpha$ of the expected cash-flow of the firm, plus the expected bribe from the manager. Using Eqs. (16) and (19), the director's expected 
payoff is

$$
\alpha x_{2}^{\mathrm{e}}+b^{\mathrm{e}}=\alpha\left(\bar{\mu}+\frac{1}{2} \Delta \mu\right)
$$

The expected payoff depends only on $\alpha$ and not on $p$. This is not surprising. The expected second-period cash-flow of a firm with a director who always fires bad managers and never fires good managers is $(1 / 2) \bar{\mu}+(1 / 2) \mu_{\mathrm{G}}=\bar{\mu}+(1 / 2) \Delta \mu$. If a director is bribed into not firing a bad manager, the expected cash-flow decreases. Hence, for a bribe to be successful, it must at least compensate the director for his loss from a reduced expected cash-flow. However, the manager will offer the lowest possible bribe, which is the one that exactly compensates for this loss.

As $p^{*} \leq \alpha^{*} \Delta \mu$, Eqs. (17) and (18) imply that $p^{\mathrm{e}} \leq c^{\mathrm{e}}$. In addition, because $W_{\mathrm{m}}>0$, one has (by Eq. (10)) that $s>0$. However, because $s$ does not affect the firing decision of the director, the shareholder can set $s$ such that the participation constraint of the manager Eq. (10) is binding.

Finally, combining Eq. (9), (Eq. (10), with equality), Eqs. (16),(18) and (20), we obtain the following expression for the shareholder value, which is to be maximised over $\alpha$ and $p$ :

$$
\mathrm{SV}=\bar{\mu}+\frac{1}{2} \frac{p+\alpha \Delta \mu}{C} \Delta \mu-W_{\mathrm{m}}-\frac{1}{2} \frac{p+\alpha \Delta \mu}{C} \frac{1}{2}(p+\alpha \Delta \mu)-\alpha\left(\bar{\mu}+\frac{1}{2} \Delta \mu\right) .
$$

From Eq. (20), $\alpha^{0}$ as defined by Eq. (12) is again the minimum value of $\alpha$ for which the participation constraint of the director is binding. Furthermore, define $\tilde{\alpha}$ as the optimum for $\alpha$ if we ignore the participation constraint for the director. In the Appendix (A) we prove the following two propositions:

Proposition 1. Suppose that $\Delta \mu>C$, that is, the expected difference between the cash-flow generated by a good or a bad manager and the cash-flow of an average manager exceeds the maximum firing cost.

(a) If $\tilde{\alpha} \leq \alpha^{0}$ (i.e., the participation constraint of the director is binding), then $\alpha^{*}=\alpha^{0}$. In this case, $p^{*}$ is equal to the minimum of $\alpha^{0} \Delta \mu$ and $C-\alpha^{0} \Delta \mu$.

(b) If $\tilde{\alpha}>\alpha^{0}$ (i.e., the participation constraint of the director is not binding at the optimal unconstrained $\alpha)$, then $\alpha^{*}=\tilde{\alpha}$ and $p^{*}=\tilde{\alpha} \Delta \mu$ at the optimal solution.

Here, $\tilde{\alpha}=\max [0, \min ((2 \Delta \mu-7 C) / 4 \Delta \mu),(C /(2 \Delta \mu))]$.

Proposition 2. Suppose that $\Delta \mu \leq C$, that is, the maximum firing cost exceeds the expected difference between the cash-flow generated by a good or a bad manager and the cash-flow of an average manager. Then, $\alpha^{*}=\alpha^{0}$ and $p^{*}$ is the minimum of $\alpha^{0} \Delta \mu$ and $\left(1-\alpha^{0}\right) \Delta \mu$.

The intuition for Proposition 1(a) is as follows. If $\tilde{\alpha} \leq \alpha^{0}$, the shareholder has to set $\alpha$ at $\alpha^{0}$, because a lower value for $\alpha$ violates the participation constraint of the director, while a higher value for $\alpha$ reduces the shareholder value, as follows from the definition of $\tilde{\alpha}$. As $\Delta \mu>C$, firing a bad manager is (ex ante) efficient for every realization of $c$. Given that a bad manager will not be fired if $c \geq p^{*}+\alpha^{*} \Delta \mu$, the shareholder sets $p$ as high as possible, with the exception that $p^{*}$ cannot be higher than $\alpha^{*} \Delta \mu$. Otherwise, a good 
manager would get fired with positive probability. This is not optimal, as we argued earlier. If $\tilde{\alpha}>\alpha^{0}$ (Proposition 1(b)), then, again by definition of $\tilde{\alpha}$, the shareholder sets $\alpha=\tilde{\alpha}$. As in Proposition 1(a), he wants to set $p$ as high as possible. That is, he sets $p=\tilde{\alpha} \Delta \mu{ }^{12}$

Although from an ex ante perspective it would always be optimal to fire a bad manager, under the optimal arrangement $\left(\alpha^{*}, p^{*}\right)$, collusion will occur with positive probability whenever $p^{*}=\alpha^{*} \Delta \mu$. The reason is as follows. The shareholder would rather set the severance payment higher in those cases. However, this would result in a good manager being fired with positive probability.

Now, suppose that $\Delta \mu \leq C$ (Proposition 2). In this case, firing a bad manager is ex ante efficient only if $c \in[0, \Delta \mu]$, because if $c>\Delta \mu$, the firing cost exceeds the expected increase in the future cash-flow. Under the optimal arrangement $\left(\alpha^{*}, p^{*}\right)$, collusion will always occur with positive probability. To avoid that a good manager can get fired, the shareholder sets $p$ at $\alpha^{0} \Delta \mu$, if $\alpha^{0} \Delta \mu<\left(1-\alpha^{0}\right) \Delta \mu$. Otherwise, he sets $p=\left(1-\alpha^{0}\right) \Delta \mu$, which prevents collusion between the bad manager and the director if $0<c \leq \Delta \mu$, but induces them to collude if $c>\Delta \mu$.

\section{When is it optimal to allow for the possibility of collusion?}

While the previous section analysed under what conditions collusion between manager and director actually occurs when collusion is allowed, in this section, we explore whether the shareholder would want to make use of the possibility to prevent collusion, if he could do so without any cost. To be precise, 'preventing collusion' means that collusion never occurs, while 'allowing for collusion' means that collusion may or may not occur, depending on the realisation of the firing cost. The analysis in this section thus bears directly upon the question whether shareholders would benefit from changes in (German and Dutch) corporate law that give them more powers to limit collusion between directors and managers. Examples of such changes are stricter information disclosure requirements (to facilitate monitoring of the director and the manager) ${ }^{13}$ and more possibilities to fire a director or a manager.

To address the issue, we need to distinguish between $\Delta \mu>C$ and $\Delta \mu \leq C$. If $\Delta \mu>C$, then firing a bad manager is always efficient from an ex ante perspective. This is precisely what a non-colluding director establishes. Hence, in this case, it would be optimal to prevent collusion.

Now, suppose that $\Delta \mu \leq C$. Hence, if $c \in[\Delta \mu, C]$, firing a bad manager would no longer be efficient from an ex ante perspective. A colluding director is bribed by a bad manager if $c \geq \alpha^{*} \Delta \mu+p^{*}$. As discussed in Section 3, this is bad for the shareholder if $c \in\left[\alpha^{*} \Delta \mu+p^{*}, \Delta \mu\right)$, but is beneficial for him if $c \in[\Delta \mu, C] .{ }^{14}$

\footnotetext{
12 The final part of the Proposition 1 implies that $\tilde{\alpha} \leq C /(2 \Delta \mu)$. The intuition is as follows. Suppose that the opposite is true, i.e. $\tilde{\alpha}>C /(2 \Delta \mu)$. In that case, the shareholder can reduce $\alpha$ and simultaneously raise $p$ without changing the firing decision of the director. This yields the same expected cash-flow, but a lower expected salary for the director, which contradicts the optimality of $\tilde{\alpha}$.

${ }^{13}$ A specific proposal recently put forward in the Netherlands is to require firms' Annual Reports to provide more details about the compensation of individual managers and directors.

${ }^{14}$ Note that $\alpha^{*} \Delta \mu+p^{*} \leq \Delta \mu$, as follows from Proposition 2.
} 
To see whether preventing collusion may be in the interest of the shareholder, we compare his losses (relative to those under the first best, see Section 3) for the case in which collusion is allowed with those for the case in which it is prevented. The first best requires that a bad manager be fired if and only if $c \in[0, \Delta \mu]$. When collusion is prevented, a bad manager is fired also when $c \in[\Delta \mu, C]$. The expected loss (relative to that for the first best) associated with preventing collusion is

$$
\frac{1}{2} \frac{C-\Delta \mu}{C}\left[\frac{1}{2}(C+\Delta \mu)-\Delta \mu\right]
$$

which is the probability that a manager is bad, $1 / 2$, multiplied by the probability that the firing decision would be (ex ante) inefficient, $(C-\Delta \mu) / C$, multiplied by the expected cash-flow loss associated with inefficient firing, $(1 / 2)(C+\Delta \mu)-\Delta \mu$.

When collusion is allowed, it takes place whenever the manager is bad and $c>\alpha^{*} \Delta \mu+$ $p^{*}$. The optimal arrangement $\left(\alpha^{*}, p^{*}\right)$ in Section 5.2 thus makes a trade-off between having collusion from time to time when this would not be ex ante efficient, i.e. if $c \in\left[\alpha^{*} \Delta \mu+\right.$ $\left.p^{*}, \Delta \mu\right)$, and collusion occurring when this is indeed ex ante efficient. Hence, the difference between the case in which collusion is allowed and the first best (see Section 3) is that, in the former case, a bad manager is not fired if $c \in\left[\alpha^{*} \Delta \mu+p^{*}, \Delta \mu\right)$. If $\left(1-\alpha^{0}\right) \Delta \mu \leq \alpha^{0} \Delta \mu$, this interval is empty (as follows from Propositions 1 and 2) and the solution with collusion being allowed in fact coincides with the first best. In the following, we therefore assume that $\left(1-\alpha^{0}\right) \Delta \mu>\alpha^{0} \Delta \mu$. Compared to the first best, the loss associated with allowing for collusion is

$$
\frac{1}{2} \frac{\Delta \mu-\left(\alpha^{*} \Delta \mu+p^{*}\right)}{C}\left[\Delta \mu-\frac{1}{2}\left(\Delta \mu+\alpha^{*} \Delta \mu+p^{*}\right)\right],
$$

which is the probability that a manager is bad, $1 / 2$, multiplied by the probability that not firing a bad manager would be (ex ante) inefficient, $\left(\Delta \mu-\left(\alpha^{*} \Delta \mu+p^{*}\right)\right) / C$, multiplied by the expected opportunity cost of not firing a bad manager, $\Delta \mu-(1 / 2)\left(\Delta \mu+\alpha^{*}\right.$ $\left.\Delta \mu+p^{*}\right)$.

Expression (22) is increasing in $C$, while expression (23) is decreasing in $C$. Hence, a larger value of $C$ increases the desirability of allowing for collusion. For $C$ sufficiently large, expression (23) is smaller than expression (22), i.e., allowing for collusion is better than preventing collusion. The reason is that the possibility of collusion offsets part of the loss associated with the failure to commit to not firing a bad manager if his firing cost is relatively high. ${ }^{15}$

\section{Concluding remarks}

In this paper, we have argued that collusion between the BoD and the management of a firm is not always bad for the shareholders of the firm. In particular, collusion alleviates the

\footnotetext{
${ }^{15}$ Note that any incentive scheme for a director with a positive relation between $x_{2}$ and his salary gives him the incentive never to fire a good manager, and always to fire a bad manager. As in the case of a linear incentive scheme, it would then be efficient to have collusion if $c \in[\Delta \mu, C]$. Hence, although one might be able to devise better incentive schemes (from the shareholder's perspective) than the linear scheme, this does not change the basic insight that it may be profitable to allow for collusion.
} 
costs associated with the failure to commit to not firing a bad manager if his personal firing cost is relatively high. The possibility of collusion reduces the compensation required by the manager.

In order for the intuition behind our results to be as clear as possible, we have deliberately kept the model simple. In particular, we have assumed the firm's performance to be independent of the manager's effort, although beyond the scope of the present paper, it would be interesting to relax this assumption. In that case, the manager's compensation scheme should be tied to the firm's performance, so as to give him the incentive to exert sufficient effort. ${ }^{16}$ Nevertheless, if the firm's performance depends both on the manager's effort and on his type, with the director being the only one to observe the manager's type, we would expect the main results in this paper to go through. Given the compensation scheme for the manager, which could depend on the firm's performance, the cash-flow produced by a bad manager still tends to be lower than that produced by a good manager. Hence, to persuade the director to not fire him, the bad manager would need to compensate the director for the expected loss in cash-flow from not replacing him. Again, collusion between manager and director may be beneficial for the shareholder, because it avoids the need to compensate the manager for relatively high realisations of his firing cost.

An interesting direction for further research would be to allow for the possibility to fire the director in the case of a bad performance by the firm or the manager. This may reduce the scope for collusion between the director and the manager. However, if allowing for collusion is in the interest of the shareholder, this would be an argument in favour of legal restrictions on the ease with which directors can be fired. In many European countries, such restrictions exist. Therefore, such an analysis could shed some light on the advantages and disadvantages of the various corporate systems that we observe. In particular, it may contribute to the current discussion about the disadvantages of the alleged shareholder short-termism in the Anglo-Saxon system (Miles, 1993, 1995; Satchell and Damant, 1995).

\section{Acknowledgements}

We thank, without implicating, Marco Haan, for detailed comments on an earlier version of this paper. We also thank seminar participants at Groningen University, Maastricht University and the University of Namur for their helpful comments. The usual disclaimer applies. Rebers gratefully acknowledges financial support from the ESR (grant no. 510-31-103). Beetsma thanks NWO for financial support (grant no. 400-70-015/ 11-3).

\footnotetext{
${ }^{16}$ Under the current set up with the cash-flow density functions exclusively determined by the quality of the match between manager and firm, the results would be unchanged if the manager's salary were tied to the firm's performance rather than being fixed. In both cases, the risk-neutral manager will, in expected terms, receive his reservation wage. If we make the expected cash-flow also dependent on manager effort, the composition of the manager's salary will no longer be irrelevant. In practice, and in particular in the US and the UK (see Abowd and Bognanno (1993)), management pay packages often contain (options on) shares in the own firm. Nevertheless, the strength of the empirical link between management pay and firm performance is a contentious issue (Conyon et al., 1995; Economist, 1995).
} 


\section{Appendix A}

In this Appendix, we prove Propositions 1 and 2. The shareholder maximises Eq. (21) over $\alpha$ and $p$. Dropping terms that do not depend on $\alpha$ and $p$, we can write the shareholder's problem as

$$
\max _{\alpha, p} \mathrm{SV}^{\prime} \equiv \frac{p+\alpha \Delta \mu}{C} \Delta \mu-\frac{p+\alpha \Delta \mu}{C} \frac{1}{2}(p+\alpha \Delta \mu)-2 \alpha\left(\bar{\mu}+\frac{1}{2} \Delta \mu\right),
$$

s.t.

$$
\begin{aligned}
& p \leq \alpha \Delta \mu, \\
& p+\alpha \Delta \mu \leq C, \\
& \alpha \geq \alpha_{0} \equiv \frac{W_{\mathrm{d}}}{\bar{\mu}+(1 / 2) \Delta \mu}, \\
& \alpha \geq 0, p \geq 0 .
\end{aligned}
$$

The first constraint has been discussed in the text and ensures that a good manager is never fired. The second constraint, also discussed in the text, ensures that the probability $(p+\alpha \Delta \mu) / C$ does not exceed 1 . The third constraint is the participation constraint of the director.

Note that

$$
\frac{\partial \mathrm{SV}^{\prime}}{\partial p}=\frac{\Delta \mu}{C}-\frac{p+\alpha \Delta \mu}{C}=0 \Leftrightarrow p=(1-\alpha) \Delta \mu
$$

Case 1. $(\Delta \mu>C)$

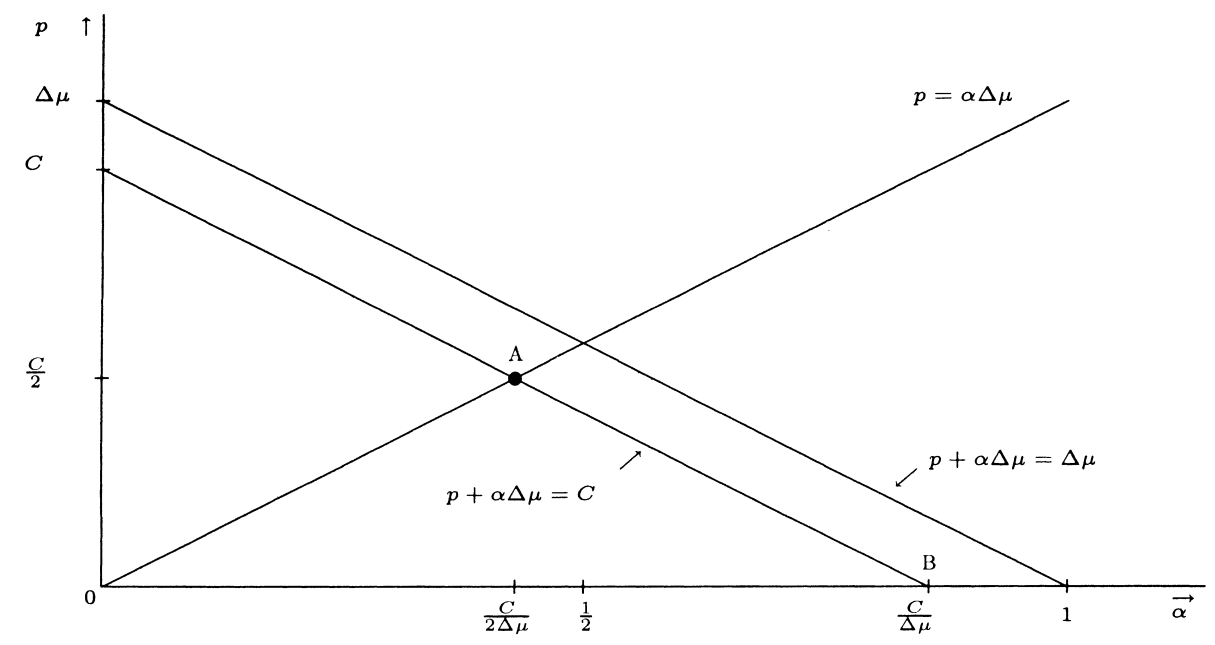


For the moment, ignore the constraint $\alpha \geq \alpha^{0}$. The admissible area is the triangle OAB. For a given $\alpha, \mathrm{SV}^{\prime}$ is a quadratic function of $p$, which reaches its maximum for $p=$ $(1-\alpha) \Delta \mu$ (Eq. (A.1)). Hence, the optimum must be located on OA or AB. Suppose that it is located on $\mathrm{AB}$. Then, $p+\alpha \Delta \mu=C$. This can be substituted into the objective function, which reduces to $\mathrm{SV}^{\prime}=\Delta \mu-(1 / 2) C-2 \alpha(\bar{\mu}+(1 / 2) \Delta \mu)$. Hence, $\alpha$ should be chosen as low as possible. Hence, if the optimum is located on $\mathrm{AB}$, it must be at A. But this implies that it is located on OA. Hence, $p=\alpha \Delta \mu$. Substitute this into the objective function to eliminate $p$. Maximise the resulting function with respect to $\alpha$ and apply the restriction that $0 \leq \alpha \leq C /(2 \Delta \mu)$ (to ensure that the optimum is located on the line piece OA). If we use in addition that $\bar{\mu}+(1 / 2) \Delta \mu=(7 / 2) \Delta \mu$ (see Fig. 1), we obtain

$$
\tilde{\alpha}=\max \left[0, \min \left(\frac{2 \Delta \mu-7 C}{4 \Delta \mu}, \frac{C}{2 \Delta \mu}\right)\right] .
$$

Finally, apply the constraint $\alpha \geq \alpha^{0}$, which we have neglected so far. As $\alpha^{0} \leq C / \Delta \mu$, as follows from Eq. (8), we have

$$
\text { If } \tilde{\alpha} \leq \alpha^{0} \text {, then } \alpha^{*}=\alpha^{0} \text { and } p^{*}= \begin{cases}\alpha^{0} \Delta \mu, & \text { if } \alpha^{0} \leq \frac{C}{2 \Delta \mu}, \\ C-\alpha^{0} \Delta \mu, & \text { if } \frac{C}{2 \Delta \mu}<\alpha^{0} \leq \frac{C}{\Delta \mu} .\end{cases}
$$

If $\tilde{\alpha}>\alpha^{0}$, then $\alpha^{*}=\tilde{\alpha}$ and $p^{*}=\tilde{\alpha} \Delta \mu$.

Case 2. $(\Delta \mu \leq C)$

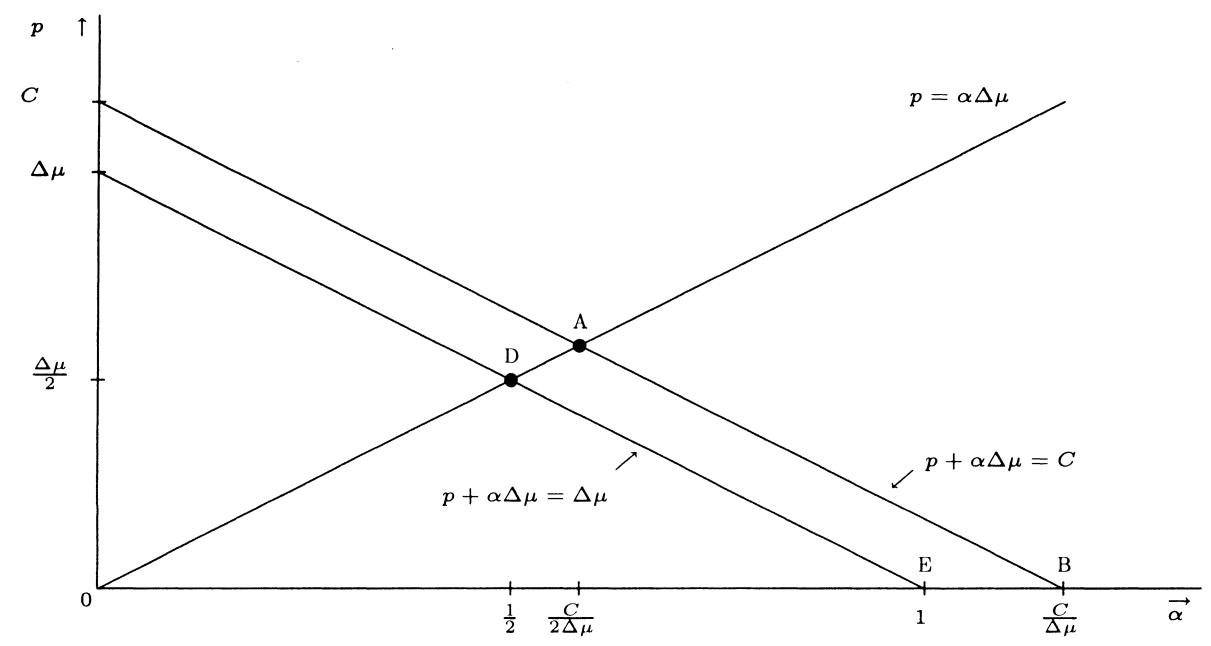


In this case, OAB is again the admissable area, and by Eq. (A.1) the optimal solution must be located on OD or on DE. As before, if the solution lies on DE, it must be located at D. Going through similar steps as in Case 1, we obtain

$$
\tilde{\alpha}=\max \left[0, \min \left(\frac{2 \Delta \mu-7 C}{4 \Delta \mu}, \frac{1}{2}\right)\right]=0 .
$$

Applying that $\alpha \geq \alpha^{0}$ yields the solution

$$
\alpha^{*}=\alpha^{0} \quad \text { and } \quad p^{*}= \begin{cases}\alpha^{0} \Delta \mu, & \text { if } \alpha^{0} \leq \frac{1}{2}, \\ \left(1-\alpha^{0}\right) \Delta \mu, & \text { if } \frac{1}{2} \leq \alpha^{0} \leq 1 .\end{cases}
$$

\section{References}

Abowd, J.M., Bognanno, M.L., 1993. International Differences in Executive and Managerial Compensation, mimeogr., Cornell University/Temple University.

Baron, D., Besanko, D., 1984. Regulation, asymmetric information and auditing. Rand Journal of Economics 15, $447-470$.

Conyon, M., Paul, G., Stephen, M., 1995. Taking care of business: executive compensation in the United Kingdom. Economic Journal 105, 704-714.

The Economist, 1995. Executive Pay: Random Numbers, Vol. 335. pp. 74-77.

Fama, E.F., 1980. Agency problems and the theory of the firm. Journal of Political Economy 88 (2), 288-307.

Garen, J.E., 1994. Executive compensation and principal-agent theory. Journal of Political Economy 102, 11751199.

Grossman, S.J., Hart, O.D., 1983. An analysis of the principal-agent problem. Econometrica 51 (1), 7-45.

Holmstrom, B., 1979. Moral hazard and observability. Bell Journal of Economics 10 (1), 74-91.

Jensen, M.C., Murphy, K.J., 1990. Performance pay and top-management incentives. Journal of Political Economy 98, 225-264.

Kofman, F., Lawarree, J., 1993. Collusion in hierarchical agency. Econometrica 61, 629-656.

Kofman, F., Lawarree, J., 1996. On the optimality of allowing collusion. Journal of Public Economics 61, 383-407.

Miles, D., 1993. Testing for short termism in the UK stock market. Economic Journal 103, 1379-1396.

Miles, D., 1995. Testing for short termism in the UK stock market: a reply. Economic Journal 105, 1224-1227.

Moerland, P.W., 1995. Alternative disciplinary mechanisms in different corporate systems. Journal of Economic Behavior and Organization 26, 17-34.

NRC, 1996. Enquête: Bestuur Bobel Schuldig aan Wanbeleid (Trans.: Inquiry: Directors and Management Bobel Guilty of Misconduct).

Ross, S.A., 1973. The economic theory of agency: the principal's problem. American Economic Review (Papers and Proceedings) 63 (2), 134-139.

Satchell, S.E., Damant, D.C., 1995. Testing for short termism in the UK stock market: a comment. Economic Journal 105, 1218-1223.

Tirole, J., 1986. Hierarchies and bureaucraties: on the role of collusion in organizations. Journal of Law Economics and Organization 2 (2), 181-214.

Volkskrant, 1993a. Nedlloyd Verlost van de Horzel (Trans.: Nedlloyd Gets Rid of its Horse-fly).

Volkskrant, 1993b. Verzekeraar Vie d'Or door directie beroofd (Trans: Insurance Company Vie d'Or Robbed by its Own Management).

Volkskrant, 1997. Rechtbank Laakt Lening Commissaris Vie d'Or (Trans.: Court Blames Loan Director Vie d'Or). 